\title{
Biochemical and Immunohistochemical Characterization of Human Fetal Ventral Mesencephalon
}

\author{
P.J. Kontur, C. Leranth, R.J. Robbins, D.D. Spencer, F. Naftolin, \\ B.S. Bunney, D.E. Redmond, Jr., and R.H. Roth \\ Neural Transplant Program, Yale University School of Medicine, \\ 333 Cedar St., New Haven, CT 06510, USA
}

The use of human fetal CNS tissue for implantation into the brains of patients with neurological disorders and for basic research requires definitive identification and characterization of the donor tissue. The presence of tyrosine hydroxylase (TH)-like immunoreactivity, the levels of various monoamines and their metabolites and the viability of enzymatically dispersed cells by trypan blue exclusion were assessed in fresh and cryopreserved-thawed human fetal ventral mesencephalic tissue of 9-12 weeks gestation. Cultures derived from fresh and cryopreserved-thawed tissue were used to assess the accumulation of $\left[{ }^{3} \mathrm{H}\right]$-dopamine (DA).

Fresh tissue exhibited TH-like immunoreactivity and contained substantial amounts of norepinephrine, DA, 3,4-dihydroxyphenylacetic acid (DOPAC), homovanillic acid (HVA), serotonin and 5-hydroxyindole acetic acid. Cryopreserved-thawed tissue also exhibited $\mathrm{TH}$-like immunoreactivity and contained substantial amounts of the monoamines and their metabolites. Unchanged levels of DA accompanied by increased DOPAC and decreased HVA levels relative to fresh tissue suggest continued metabolic function of the dopamine-containing neurons in cryopreserved-thawed tissue.

The viability of fresh and cryopreservedthawed ventral mesencephalon was assessed by trypan blue exclusion prior to the preparation of cultures derived from the tissue. The viability of the fresh and thawed tissue did not differ. Cultures of ventral mesencephalon derived from fresh and cryopreserved-thawed tissue contained $\mathrm{TH}$-immunoreactive neurons and were able to accumulate $\left[{ }^{3} \mathrm{H}\right]-D A$. A portion of the uptake (approximately 35-50\%) in cultures from fresh or cryopreserved-thawed tissue was sensitive to blockade by the monoamine uptake inhibitor cocaine.

Early gestational human fetal ventral mesencephalon contains $\mathrm{TH}$ and is capable of DA metabolism as indicated by the presence of DA and the metabolites DOPAC and HVA. Culturing of fresh and cryopreserved-thawed human fetal ventral mesencephalon demonstrates that DA neurons within the tissue are viable, and retain the ability to differentiate and express neurochemical function, as measured by the uptake of tritiated dopamine. Cryopreservation does not appear to have a major adverse effect on the viability of mesencephalic DA neurons.

Supported entirely by private funds generously provided by the G. Harold and Leila Y. Mathers Charitable Foundation and the Axion Research Foundation. 

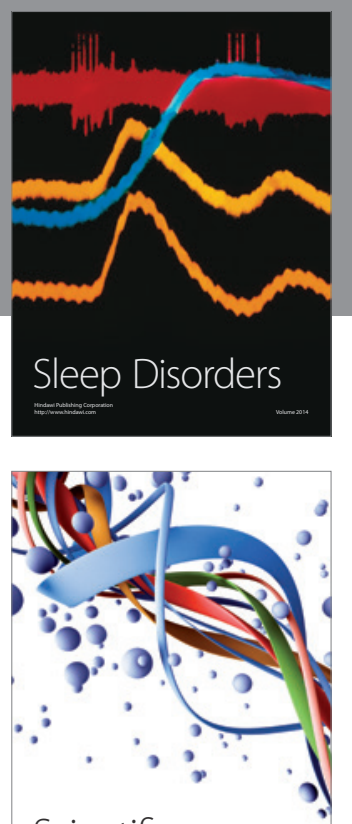

Scientifica
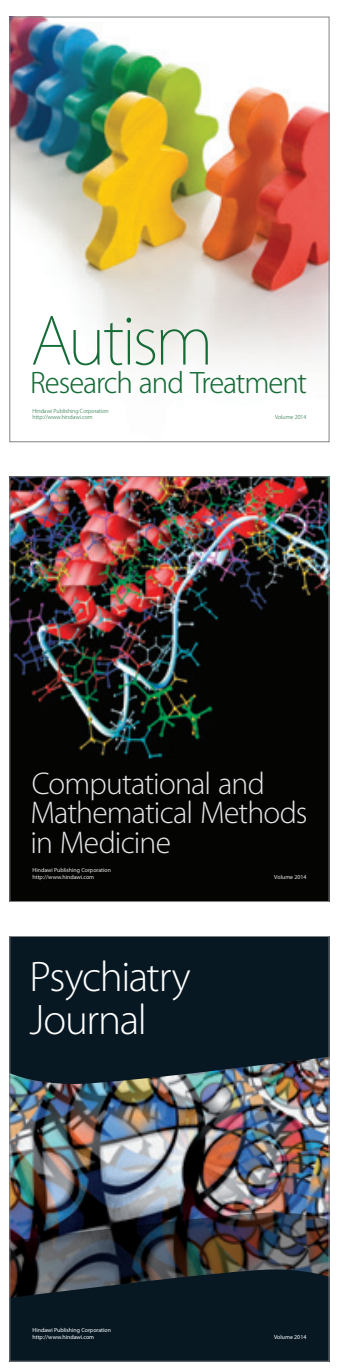
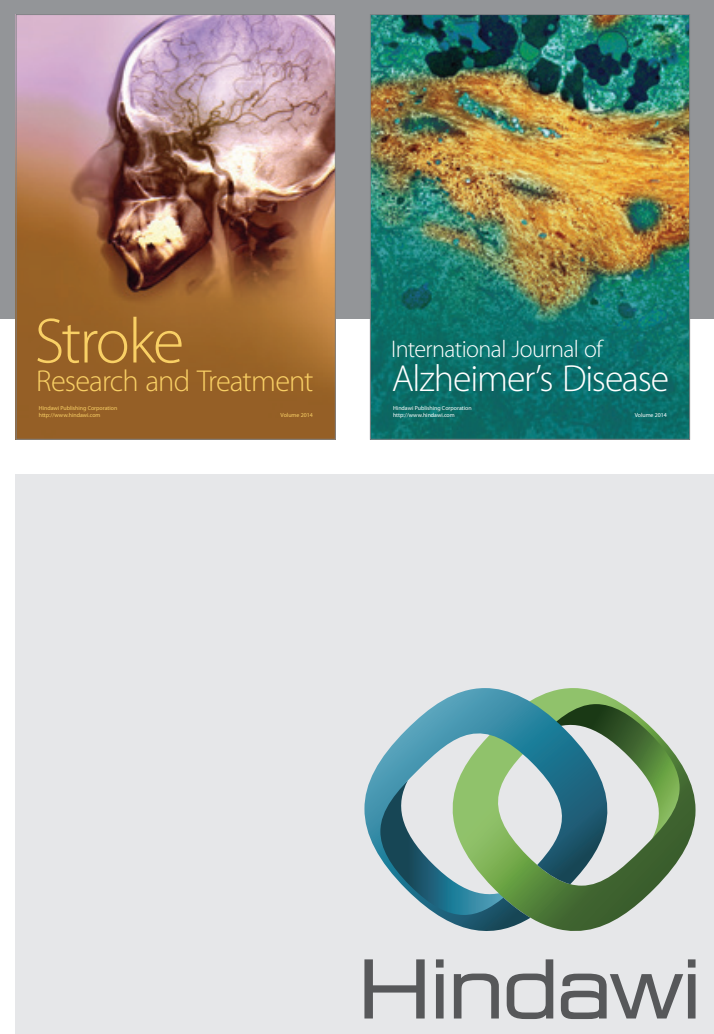

Submit your manuscripts at

http://www.hindawi.com
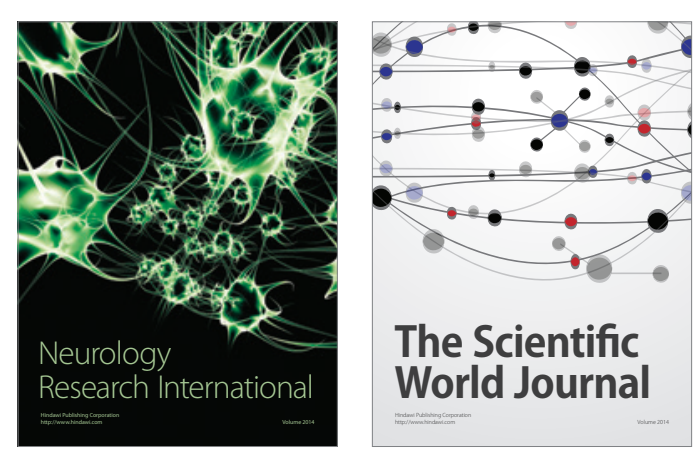

The Scientific World Journal

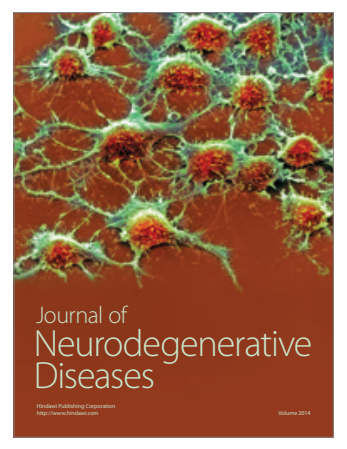

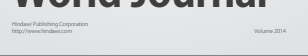

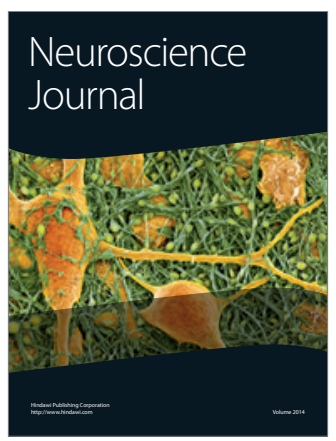

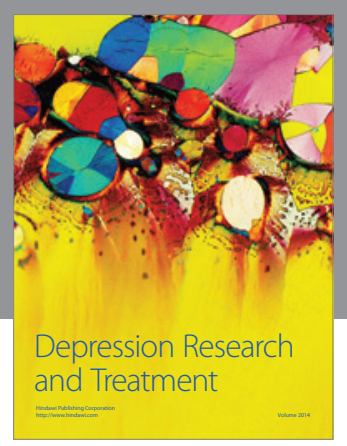
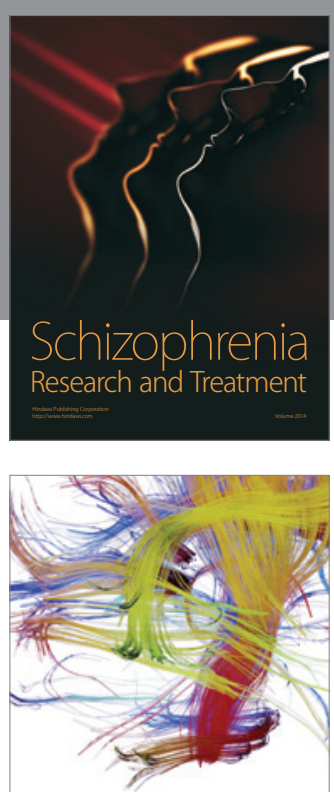

Brain Science

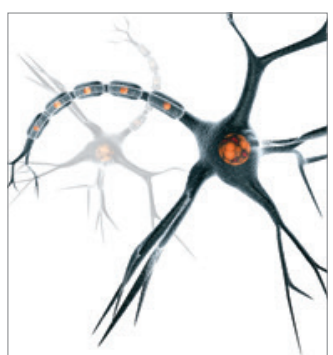

Neural Plasticity
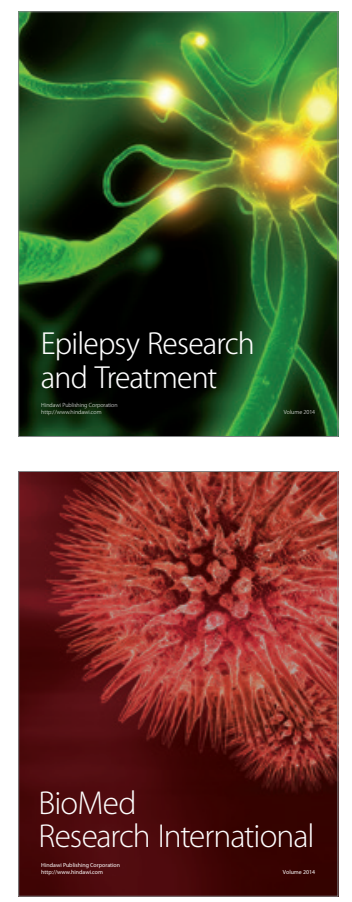

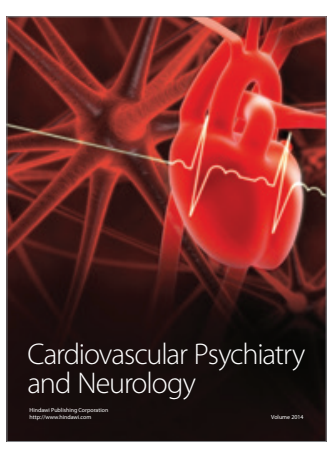

Parkinson's

Disease
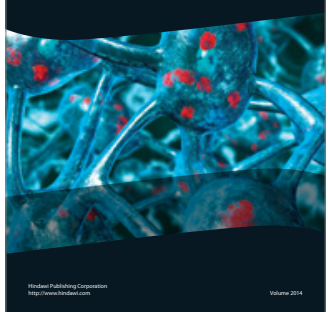